\title{
An Overlooked Indicator of Edtech Quality: The Use of Learning Sciences Research
}

Parker Van Nostrand, Sierra Noakes, Zohal Shah, \& Christina Luke Luna

February 2022
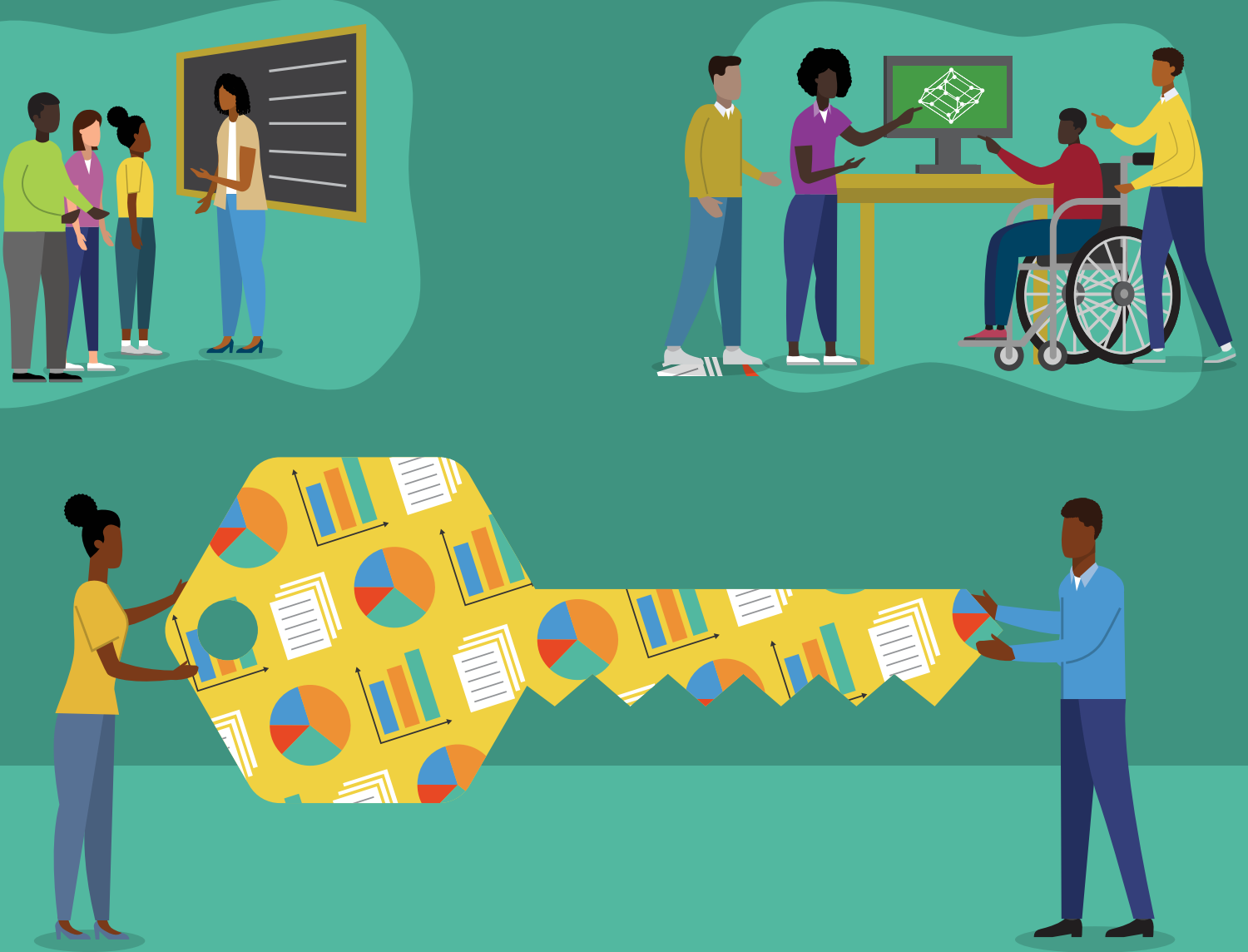


\section{Table of Contents}

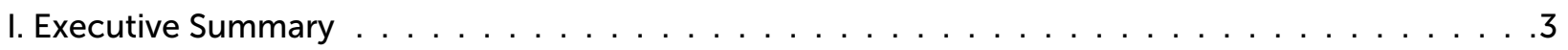

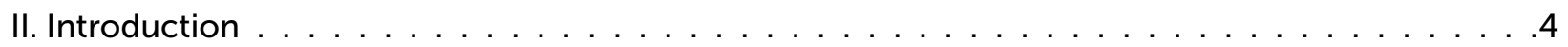

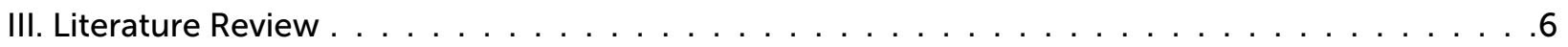

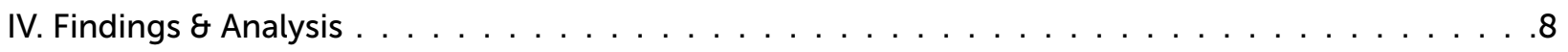

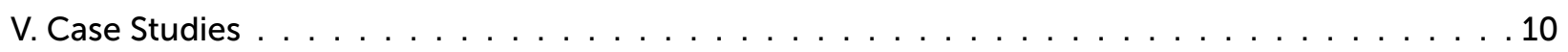

Committing to Research Across Different Product Types . . . . . . . . . . . . . 11

Using Research to Craft a Theoretical Framework - and Beyond . . . . . . . . . . 13

Integrating Research in a Cross-Functional Team . . . . . . . . . . . . . . 15

Using Research to Understand Which Metrics Matter . . . . . . . . . . . . . . . 16

The Long-Awaited Marriage Between Research and Practice. . . . . . . . . . . . . . . 17

VI. Research-Based Design Product Certification: The Next Iteration . . . . . . . . . . . . . . . 19

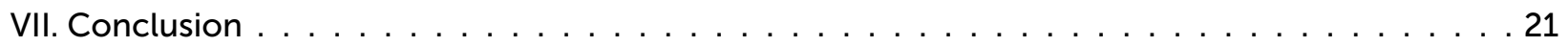

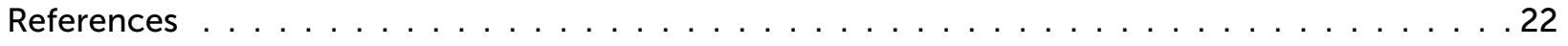

\section{Suggested Citation}

Van Nostrand, P., Noakes, S., Shah, Z., \& Luke Luna C. (2022, February). An overlooked indicator of edtech quality: The use of learning sciences research. Digital Promise. https://doi.org/10.51388/20.500.12265/150 


\section{Executive Summary}

Learning sciences research uncovers how people learn best and has the potential to enable technology to build powerful learning opportunities. We can see through a well known example, Sesame Street, that innovative approaches to leveraging technology to support

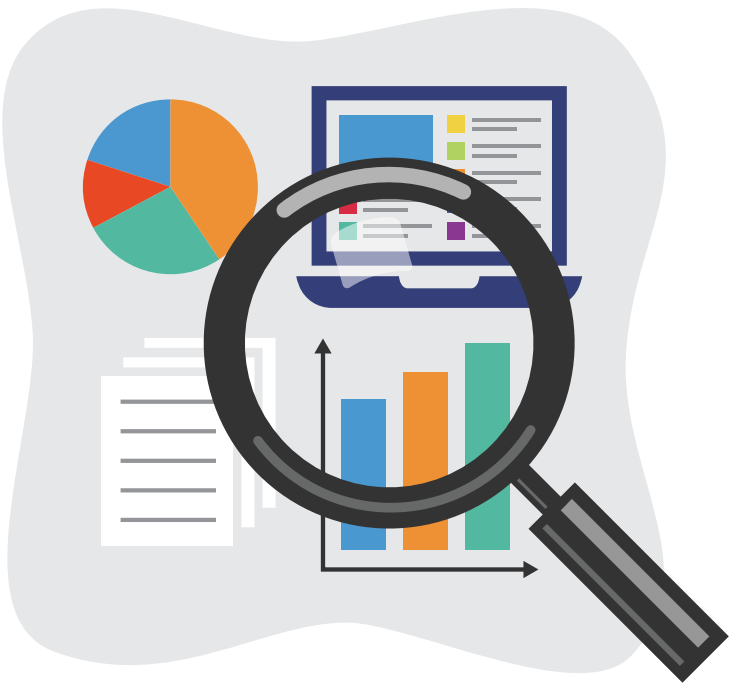
learning are made more meaningful with an intentional and ongoing connection to research about learning. This report explores the ways in which several edtech products focus their efforts on an intended learning purpose, consult and integrate research in their design, and strive to achieve their articulated goal.

Through our own research with over 25 edtech products, we heard resoundingly that the use of learning sciences research enables edtech tools to more clearly name the expected impact on learning and more easily evaluate the product's impact on learning. We learned that products integrating learning sciences tend to stay dynamic and connected to the field. Additionally, we learned that products that plan and design backwards from a research-based goal can better track progress towards that goal and its impact on learning.

The five case studies included in the report provide examples of and best practices for leveraging research at multiple phases of product development, including acquisition, establishing cross-functional teams to collaboratively leverage learning sciences research, and using research to understand the best ways to measure success.

Digital Promise has incorporated this learning into the relaunch of the Research-Based Design Product Certification to support practitioners in finding high-quality tools and celebrate products that are demonstrating research-based design. 


\section{Introduction}

The education system's increased reliance on education technology (edtech) underscores the essential question: How do we know whether a product will support learning in meaningful ways?

Today, education leaders often turn to efficacy studies to determine the quality of edtech tools. While efficacy studies tend to be the go-to for determining product quality, there are a lot of challenges with this exclusive metric of success. For one, these studies take years to produce, creating a lag time that may render results less relevant to the constantly evolving learning ecosystems across the country. Further, new edtech products cannot immediately engage in multi-year randomized control trials. The idea of only using efficacy studies to determine quality also excludes the prolific rate at which products are introduced to the market. Another challenge is the generalizability of studies that emphasize mean effects and deemphasize contextual variables. Context matters tremendously and with so many variables at play in edtech efficacy studies, it is difficult to determine whether the findings are replicable, even when conducted by thoughtful researchers.

The potential-and essential role-of edtech in learning is indisputable, which calls for a new approach to measuring product quality. Research demonstrates that to facilitate learning experiences, products
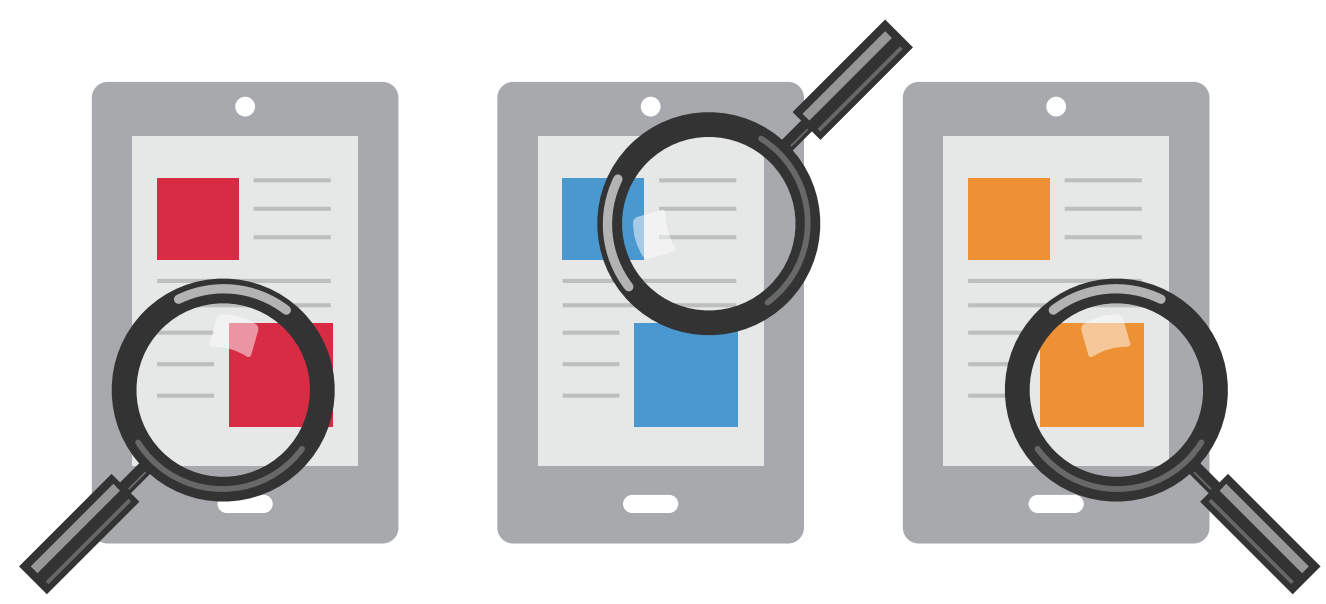
must design with intention and alignment to pedagogical principles uncovered through learning sciences research. In fact, products designed based on developers' limited understanding of learning may actually perpetuate harmful misunderstandings about the way people learn in the product itself (Hirsh-Pasek et al., 2015). Products that support meaningful learning must be designed with a specific learning purpose and offer research-based scaffolding to support learning throughout the product.

Digital Promise, along with our thought partners who work in classrooms, schools, districts, and nonprofits, advocates for the field to leverage research-based design as a leading metric for evaluating edtech quality. By asking edtech developers to share the product's purpose along with a clear explanation of the learning sciences research used to drive decisions in product design-from creating a theoretical framework to guide product design to specific design decisions within the too-we can begin to differentiate products authentically working to solve real challenges in education from products that are likely out of touch with the needs of classrooms and the best practices understood in educational research.

When Digital Promise launched the Research-Based Design Product Certification two years ago, the team worked with representatives from school and district leadership, coaches, and teachers to understand what types of information they wanted confirmed by a trustworthy third party. Resoundingly, we heard concern about knowing whether a product was worth the money, time, and resources needed to implement it. We 
decided the most timely and generalizable approach to begin creating transparency around this focal point was to look at the ways in which a product consulted learning sciences research to drive design decisions. The Digital Promise team's idea was to ask questions such as: Does the product have an underlying plan behind what the tool is expected to accomplish? Was rigorous research consulted throughout the process to design this plan?

Through this report, our team explores the importance of research-based design in edtech. In the Literature Review, we consider the absence of peer-reviewed efficacy research in the edtech field and look to Sesame Street as a model for innovative, research-based learning that leads to measurable impact on children. In the Findings \& Analysis and Case Studies sections, the report presents our learnings from a survey with over 25 edtech developer respondents and five case studies that serve as examples of how products successfully embed learning sciences research in their design. We provide an overview of the updates made to the Research-Based Design Product Certification and conclude with opportunities for individuals to leverage this new indicator of edtech quality. 


\section{Literature Review}

As education trends toward the digital, we must ask ourselves how this great reshaping may best serve students, particularly those from marginalized backgrounds. A proliferation of commercially available products has given educators and families unprecedented choice in how to construct digital learning experiences. Apple alone claims that more than 75,000 educational apps are available for download in its App Store. Many, if not most, of these products are unregulated and untested for learning in any meaningful way (Hirsh-Pasek et al., 2015). The rapid growth of this industry has made it difficult to understand the impact that edtech products have on learning outcomes, both in terms of an individual product and the field as a whole. With edtech being in such high demand, companies often develop products at a speed that compromises the possibility for research-informed pedagogical practices to form the basis of design (Hamilton et al., 2020; Manches \& Plowman, 2017).

While the current research on the educational value of edtech products is thin, there is promising evidence that digital products have the potential to create, or supplement, meaningful learning opportunities. For example, digital tools have been found to have a positive effect on cognitive development (Schute et al., 2015). In particular, the use of game-like structures, which many edtech products incorporate, can have a stronger effect on cognitive outcomes compared to non-game settings (Clark et al., 2014). Beyond cognitive learning, digital tools can have a positive impact on motivation

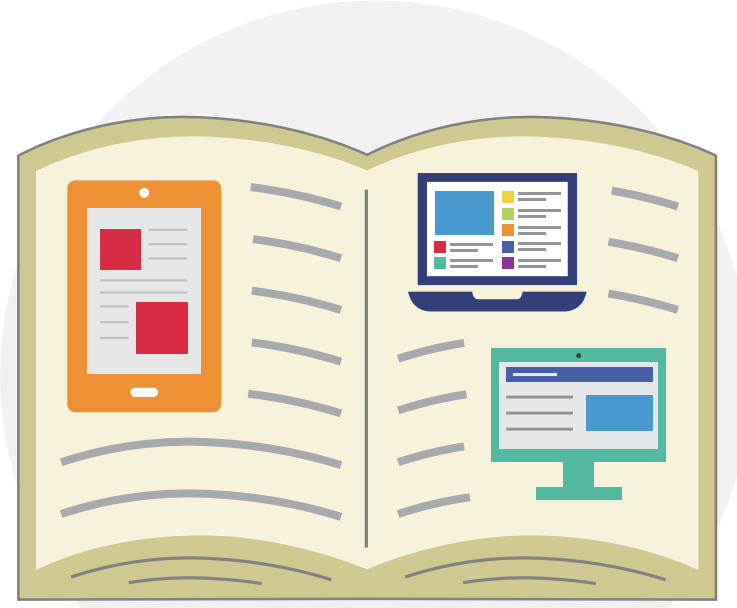
and the ability to collaborate (Erhel \& Jamet, 2013; Habgood \& Ainsworth, 2011; Miller, 2018). Products can also help students learn in subject-specific areas, such as literacy (Barone \& Wright, 2008; Hutchison et al., 2012), science (Clark et al., 2011; Zydney \& Warner, 2016), and math (Cheung \& Slavin, 2013; Griffith et al., 2020).

The potential for digital and online spaces to facilitate learning is undeniably there, but learning cannot take place without the intentional application of pedagogical principles. Despite best intentions, developers who do not engage meaningfully with learning sciences research will be misguided in their attempts to construct educational opportunities. Instead, they will be influenced by "current trends in technology and design, their own interactions with technology, and their experiences and intuitive sense of how learning happens or what children will find enjoyable," which may propagate incorrect or harmful misconceptions about learning (Hirsh-Pasek et al., 2015, p. 4). Some researchers have attempted to distill the core aspects of digital products to evaluate whether they engender genuine learning opportunities. Ke (2016) identified the type of learning, the tool's attributes, and how the product is used in the teaching or learning process as three key components that developers must consider when building products to be educational. Taking a different approach, Hirsh-Pasek et al. (2015) recognized products as educational if they promoted "active, engaged, meaningful, and socially interactive learning within the context of a supported learning goal" (p. 3). Designers must be intentional and specific about what learning a tool is meant to induce, the context it will 
be used in, and how support for students will be scaffolded throughout. All of these considerations are best informed by research on learning, and not by creators' intuitions or following of trends.

Research on the effectiveness of digital resources is often demonstrated in lab settings with tools that were specifically designed for the study, and involve a discussion of the pedagogical principles at play. A comparable examination of commercial products is yet to be rigorously applied (Lee, 2021). The dearth of research on the connection between theoretical framework and learning outcomes in the commercial space leaves unanswered questions about how learning sciences are being applied to these widely available edtech products.

To illuminate the importance of learning research for the development of publicly accessible educational tools, we can turn to a decades-old property: Sesame Street. In the same way that questions have been raised about the educational value of digital products in a new digital world, Sesame Street was a pioneer in leveraging television programming to teach children academic skills at a time when broadcast media was not used for such purpose. The creators of Sesame Street sought to develop a tool that would bring about real learning for all children who viewed the program, and in particular combat the gap in school readiness. To do this, the team utilized a model that combined curriculum development, formative research (a look into prior literature to determine children's learning needs), and summative research (an examination of Sesame Street's ongoing impact on its viewers) to generate and refine the production process (Revelle, 2003; Truglio \& Fisch, 2001). The series was and continues to be an educational success, with over a thousand studies shedding light on the impact of its research-based and -backed model (Cooney, 2001). The learning promise of the program is evident in academic as well as creative and social arenas (Choi, 2021; Fisch, 2004; Mares \& Pan, 2013; Mares \& Woodard, 2005; Revelle et al., 2001).

As a television program, Sesame Street is interactive in the sense that it invites its young viewers to respond to and work through various situational prompts, though the program, of course, moves along at a predetermined pace. The team behind the series would later develop interactive educational software-an early version of some of the edtech products today-utilizing the same basis in summative and formative research to support learning outcomes (Revelle et al., 2001). The through line here is evident: new modes of technology and methods of instruction will continue to emerge, and it is through a foundation in learning sciences research that products can meaningfully support students and leave a legacy of impact.

Educational technology brings about its own challenges and opportunities for leveraging existing research. A crucial area to examine is the burgeoning field of human-computer interaction, and in particular, child-computer interaction for products aimed at early childhood and K-12, to understand how learning frameworks may best be mapped onto product design (Antle, 2007; Gelderblom \& Kotzé, 2009; Giannakos et al., 2020). Designers of children's technology who are aware of the developmental needs of young learners are better equipped to produce innovative products (Bekker \& Antle, 2011). Edtech developers should follow new methods in big data analysis to engage in reflective research to uncover how user outcomes align with the product's theoretical underpinnings (Dede, 2019).

Success for students and the educators who work with them is reliant on thoughtful, intentional design that centers relevant bodies of research. The lack of research on the current crop of commercial products indicates that we are still in the early stages of this digital shift in education. We still have much to learn about how products serve learners, but the answer to this question will be found more readily when the movement includes more products that engage with the learning sciences. 


\section{Findings \& Analysis}

The Digital Promise team has engaged closely with education leaders for a decade to understand their priorities with edtech and stayed up to date on research about edtech. However, we have rarely asked edtech developers themselves what best practices they see going into the most successful products. In December 2021, our team invited products that have earned the Research-Based Design Product Certification to share more about their perspectives on the use of learning sciences research in edtech design. We heard from over 25 edtech products through a survey that learning sciences research is fundamental to the work they do. Additionally, we

"One of the things I appreciate most about the learning sciences community is that we're always looking into what's next to best support the students and educators we serve. Research isn't static. Research is always changing and we're continually building upon it and learning from it to develop educational programs in both digital and print formats that help students and educators reach their full potential."

- Yelee Jo (she/her), Director of Research \& Validation, Scholastic Education Solutions conducted five case studies with products that have earned the certification to more deeply explore the ways products can leverage learning sciences research from product conception through ongoing and iterative design. Below, we explore those findings.

\section{Edtech Professional Survey Responses}

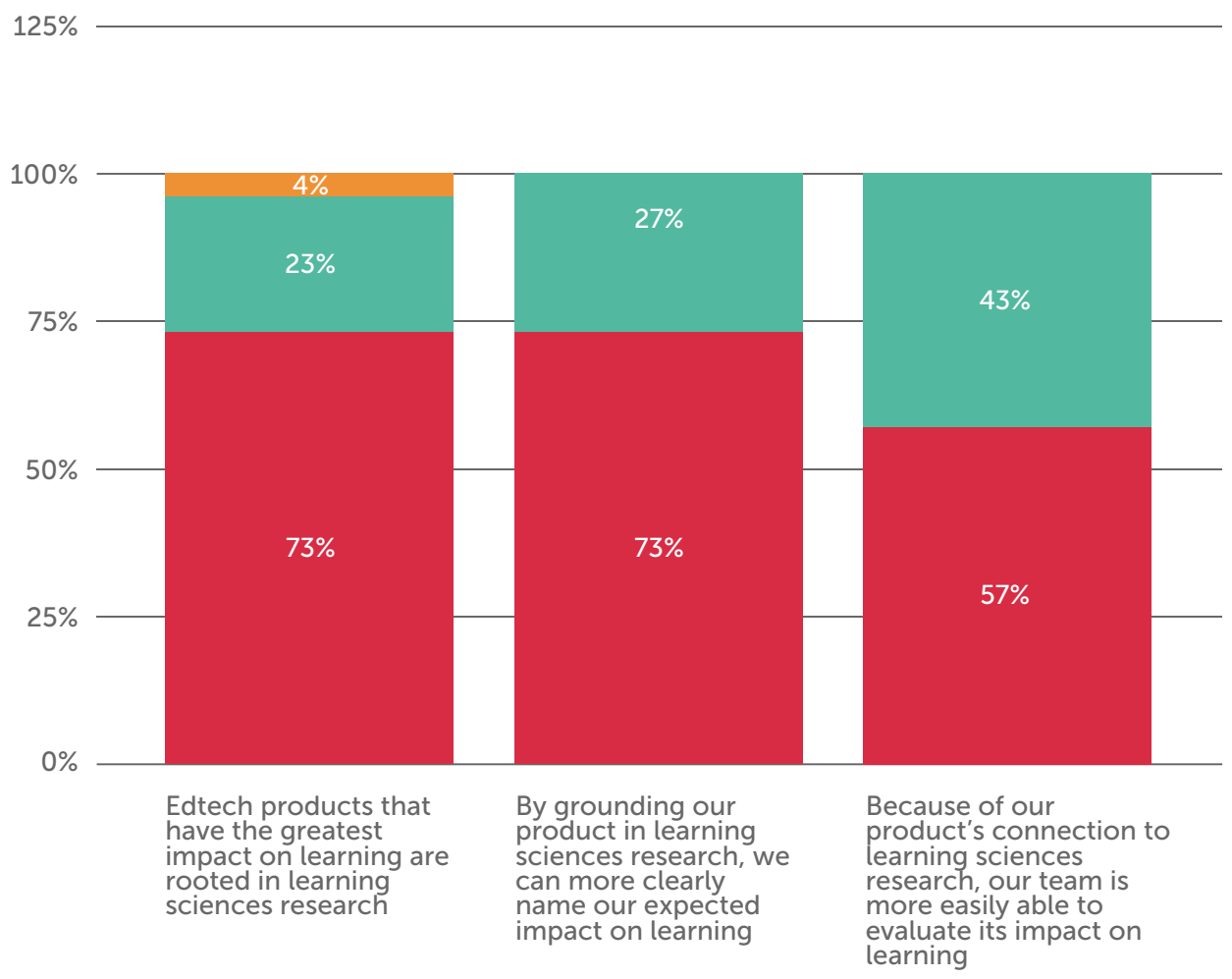

\section{Disagree \\ Agree \\ Strongly Agree}

Figure 1. A bar graph showing the level of product's agreement with the impact leveraging learning sciences research has on edtech, including products' ability to more clearly name expected impact on learning and easier ability to evaluate impact on learning. 
"Teachers and practitioners don't get

access to best practices that come from

research, and we have to fix that. And the

only way to fix that is for there to be more

conversations between the two, to have

more products and schools and platforms

that use research, and for that research

to have actionable recommendations for

practitioners..."

- Dr. Katie Brown, (she/her), Founder and Chief

Education Officer, EnGen
Overall, the survey responses emphasized the value of learning sciences research in helping maximize learner outcomes, create tools for measurement, facilitate powerful learning experiences, and promote student-centered learning. Seventy-three percent of the respondents strongly agreed that edtech products rooted in research foundations have the greatest impact. Moreover, all respondents strongly agreed (73\%) or agreed $(27 \%)$ that due to their foundation in learning sciences research, they are more clearly able to name their product's expected impact on learning and strongly agreed $(57 \%)$ or agreed $(43 \%)$ that they are able to more easily evaluate their product's impact on learning.

To gain a deeper understanding on the value of incorporating learning sciences research throughout the product development process, we wanted to learn about the value edtech products gain when using research to drive design decisions. Three themes emerged from the open-ended survey responses and case studies that provide insights into the impact leveraging learning sciences research has for educators, learners, researchers, and edtech as an agent for change in education.

\section{Learning and development as a practice and industry is not fixed, and incorporating learning sciences research ensures product design and development can be as dynamic as the evolution of educational research.}

Leveraging research provides product developers with ongoing opportunities to learn about best practices that emerge from new learning sciences studies as well as contribute to the growing body of literature on a particular domain of learning. For example, Dr. Katie Brown frequently contributes to peer reviewed literature on language learning using data from EnGen's platform. Developers and researchers in edtech may find successful examples along the way that can be implemented and tested for their products and/or share their findings from their product(s) that can further inform the field.

\section{Relationships between researchers, teachers, school and district leaders, and edtech developers can increase outcomes and bridge barriers to implementation.}

The inclusion of educator, student, and practitioner voices in edtech development is powerful; their expertise and first-hand experiences with learning can help researchers create actionable recommendations that support intended outcomes. Closing the research-practice gap through such formalized partnerships can provide insights into the challenges faced in both, in school and out-of-school settings, that can lead to sustainable and successful implementation practices for edtech. 


\section{Learning sciences research enables} products to start with an anticipated outcome and build a tool intended to achieve that goal.

Integrating research into the product design process can inform the creation of features that directly support the intended impact for educators and learners. Learning sciences have a repository of literature for organizations to find tools and resources that support both measurement and educational theory that are essential to promoting learning and developmental outcomes.

\section{Case Studies}

Our team conducted five case studies with products that have earned the Research-Based Design Product Certification to learn more about best practices. Through our interviews, we learned how products are using research to inform development of products from scratch, to define success metrics, and to build a collaborative and cross-functional team. The following case studies are intended to support products in solving challenges they may face when designing an edtech tool based on research, at any stage. 


\section{Case Study:}

Committing to Research Across Different Product Types
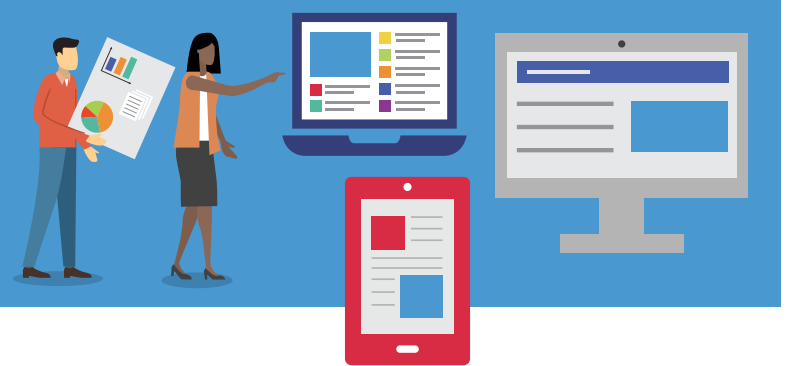

To make a measurable impact on its learners, an edtech company needs to solidify a cohesive vision for its use of research, even across multiple products that may have ended up in its portfolio through different processes. Digital Promise awarded the Research-Based Design Product Certification to two literacy products that exemplify establishing a research-based vision: Scholastic F.I.R.S.T. and Scholastic W.O.R.D. Through our conversation with Yelee Jo (she/her), Director of Research \& Validation, Scholastic Education Solutions, and Suzanne Lucas (she/her), Vice President of Digital Product Marketing, Scholastic Education Solutions, we learned more about the Scholastic team's efforts to leverage learning sciences research to get these products into the hands of educators and students. Scholastic W.O.R.D. was created in-house and built from the ground up, whereas Scholastic F.I.R.S.T. was acquired, having previously been known as Ooka Island. Regardless of how these products ended up in the company's catalog, learning sciences research has played a critical role in transforming these resources from ideas to actual tools utilized by Scholastic's users.

To create Scholastic W.O.R.D. from scratch, the team started with a specific end goal in mind: develop a solid foundation of words needed to succeed in literacy. The team started by partnering with vocabulary researcher Dr. Elfrieda Hiebert to identify the learning sciences research that informs how students could achieve this goal. For vocabulary acquisition, this might be teaching words and morphological word families across multiple

"We are not building products just for the sake of building products. We're asking how we can solve for the problems that exist today."

- Suzanne Lucas (she/her), Vice President of Digital Product Marketing, Scholastic Education Solutions

contexts to deepen comprehension. Intentionality is key to the design of high-quality edtech products, Lucas explained. "We are not building products just for the sake of building products. We're asking how we can solve for the problems that exist today."

Diving into learning sciences research was also a crucial step in the decision to acquire Ooka Island, which would eventually become Scholastic F.I.R.S.T. It was necessary for Scholastic to know that this product would stand out in a crowded market when held up to the strict standards for design based on high-quality research. The program's creator, Dr. Kay MacPhee, had thoroughly documented the foundational reading skills research used to build the platform. As a research practitioner, she was constantly evaluating how the program was serving its users at the time. Through participating in continual dialog with Dr. MacPhee and reviewing the building blocks of Ooka Island, Scholastic felt confident in the product's ability to drive the intended learning results, which ultimately led to the acquisition. 
"For all products that we bring to market, it is essential to have clear structures in place to ensure that research is being used purposefully and effectively, and we are incorporating feedback from educators from the beginning," said Jo. Both instances-building a product from the ground up and acquiring one-have their own challenges, and require different processes for engaging with research. "It isn't harder or easier either way," Jo explained, noting that certain structures need to be in place to make sure that research is being used purposefully and effectively. Creating a novel tool demands the kind of results-oriented planning that's only possible with the aid of learning sciences research. On the other hand, acquiring an existing product makes it possible to build off of something already successful, though only where there exists a clear vision and a solid research foundation that is thoughtfully communicated and accessible to evaluation.

The insistence on using research-based design is an evident through line in Scholastic's 100-year history, no matter the type of product. "The importance of practitioner research and understanding what is needed in the classroom is the backbone of our organization," said Lucas. "The very first Scholastic magazine in 1920 started with a focus group of principals." 
2. Case Study:

Using Research to Craft a Theoretical Framework - and Beyond

\section{Theoretical}
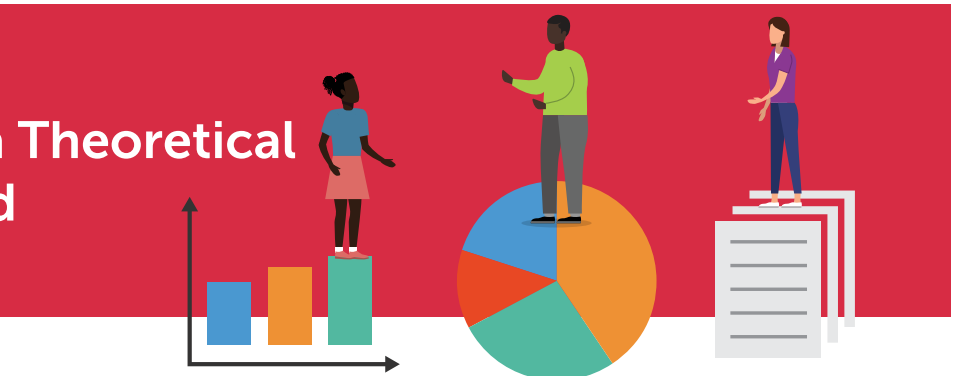

For Dr. Lara Triona (she/her), Vice President of Learning Sciences at Levered Learning, edtech products can miss the mark when it comes to crafting meaningful educational experiences. "There's this assumption in edtech that you just plop a kid in front of a computer and, voilà, now you have these fancy results," Dr. Triona opined. Results don't come from a product just being novel or having an eye-catching user interface. Instead, it takes a grounding in research from conception and a realized theory of education to provide the structured support for student success. For Levered, this means putting student-centered learning at the crux of its upper elementary mathematics curriculum. This philosophy utilizes methodologies that grant students autonomy, where agency is key in the learning experience and their own decision-making drives outcomes. Another component of student-centered learning is competency-based instruction, where teachers are able to provide support as needed

"Companies should be using learning sciences differently at different time points."

- Dr. Lara Triona (she/her), Vice President of Learning Sciences, Levered Learning informed by the real-time formative assessment data Levered provides. Within a math context, student-centered learning can take the shape of providing pupils with a platform that develops their independent exploration and problem-solving skills while giving teachers the data and planning tools that they need to make critical instructional decisions. By learning through research, the team at Levered was able to build the product's theoretical framework firmly rooted in this ideology.

But using research as a basis for design is not a one-and-done game. Dr. Triona emphasized that "companies should be using learning sciences differently at different time points" in their product development and company growth. It's important to consider how research can inform every step along the way past the point of establishing a theoretical framework. For example, early-stage startups may need to initially focus on scouring the literature on building well-rounded curricula. Research is also useful for interpreting what kinds of skill-building national and state standards are trying to prompt. Down the road, a company should devote more resources to analyzing how their product is actually being used within the intended pedagogical framework. And what kind of research is up next for Levered? "Our goal is to eventually expand worldwide," stated Dr. Triona, "so that would involve a lot of research on subject-specific localization." In the meantime, Levered is working with schools in a wide range of communities in the U.S. to learn how the program can be most effective for students of all populations, abilities, and cultural backgrounds.

While their product was built on learning sciences research, the Levered team received an unexpected source of validation for their product's design and philosophy when the COVID-19 pandemic impacted classrooms across the country. Levered found that classrooms that had used their 
math products for longer were able to transition with the program to the remote learning space more seamlessly than newer partners. Dr. Triona credited the success here in part to the emphasis placed on student-centered design, which enabled more congruity between the in-person and remote experiences. In other words, students had developed a degree of autonomy in their math lessons and teachers had developed a meaningful relationship with each student that transcended the specific context of their in-person classroom. The research-based theoretical framework Levered used proved beneficial even in a circumstance that couldn't be predicted. 


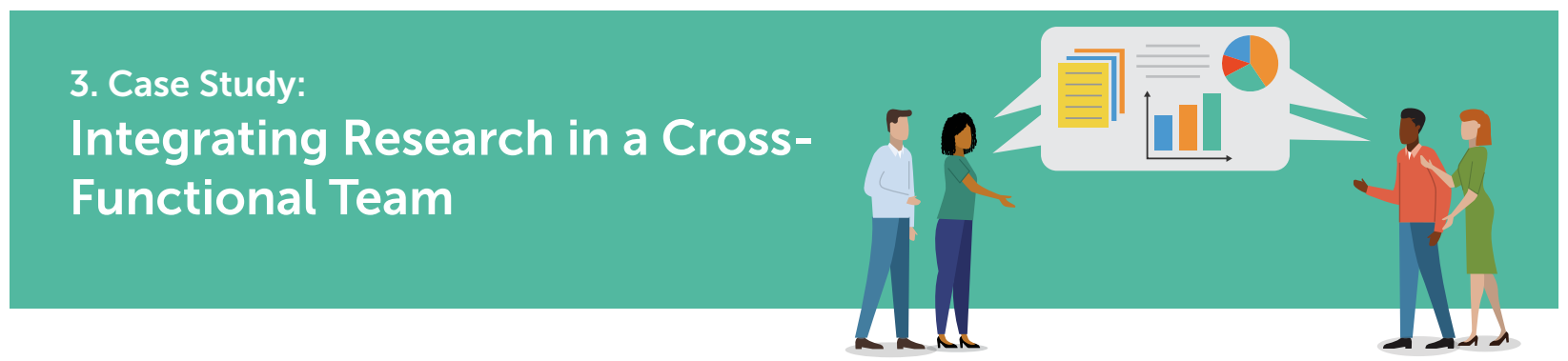

Getting all team members to buy into a project equally is a challenge, particularly in edtech where idealism may not be easily compatible with design realities. "Very often, the edtech industry ends up forgetting about the 'ed-' at the beginning of the '-tech,' and they become very 'tech,'" observed Dr. Susanne Nobles (she/her), Chief Academic Officer at ReadWorks. "And 'ed' is first for a reason." ReadWorks is a nonprofit organization that seeks to close the literacy gap by providing educators with a digital library of high quality reading materials and instructional resources, and whose basis in cognitive science research has been recognized by Digital Promise.

It's not just this basis in learning sciences research that drives ReadWorks' creation of new products and features, but also the dedication to integrating teams to mesh what's optimal for learning with what's possible from a technical standpoint. Product managers and software engineers don't often have a background in education, and the same is true of educators and digital product development. As a result, a lack of dialog between the disparate teams may seed a degree of tension if both groups come to the table with a mindset of

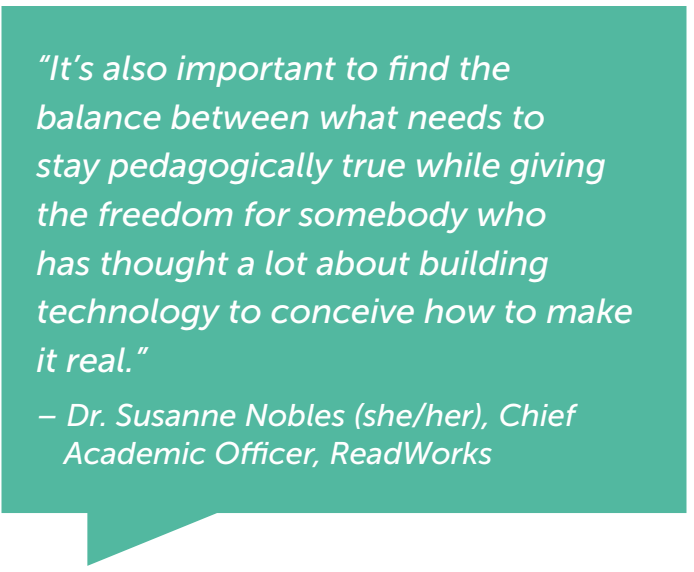
being the expert in the room. "And while they are experts, it's also important to find the balance between what needs to stay pedagogically true while giving the freedom for somebody who has thought a lot about building technology to conceive how to make it real," Dr. Nobles pointed out. Without the proper communication, what started as a plan carefully constructed from learning research may end up unrecognizable by the time it comes out the other end, even with the best of intentions.

To combat this issue, Dr. Nobles explained that the team members at ReadWorks schedule regular cross-functional meetings to make sure that knowledge is constantly being transferred and that any updates or changes are discussed immediately. Even when the different groups think there might not be something specific to check in about, they still do anyway, which fosters a sense of trust and reinforces a belief in their mutual goals. Doing so also empowers both sides: the educators come to understand the potentials of the technology more clearly, and the developers gain a greater awareness of the "why" behind what they're creating.

As Dr. Nobles said, the "ed-" is first in edtech, but it takes a concerted effort to make sure it's not there superficially. 


\section{Case Study:}

\section{Using Research to Understand Which Metrics Matter}

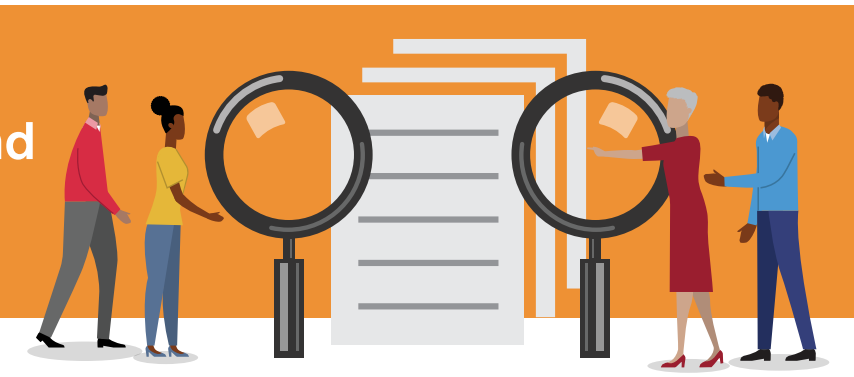

How do you know that the product you're developing functions as intended? That it's engaging? Worthwhile? Any developer will be able to rattle off a number of metrics that point you in a direction. But how many of those variables would indicate a genuinely meaningful learning experience? For Dr. Katie Brown (she/her), Founder and Chief Education Officer of the adult English language acquisition platform EnGen, leveraging research is key to understanding the right kinds of metrics needed to show the power of your product. "If you do that at the front-end of building your platform, it's very easy to show that it works down the line," Dr. Brown stated.

Thinking about the research framework at the heart of your product enables designers to look beyond traditional metrics used in tech. Too often, Dr. Brown explained, "user research is conflated with learner research, and we shouldn't do that." Number of clicks or time spent on a page may be meaningful information on one app, but rarely paints the full picture in an edtech context. What a user wants is not necessarily what a learner needs. Without diving into the research to know how to assess specific educational outcomes, learner needs can get lost in the shuffle.

It can be challenging to know what kinds of learner research will serve as useful theoretical underpinnings for your product and its outcomes.

Dr. Brown recommended breaking down the core components that comprise your product idea and digging into the literature about each topic. For example, since EnGen is a distance language learning product, Dr. Brown asked the following

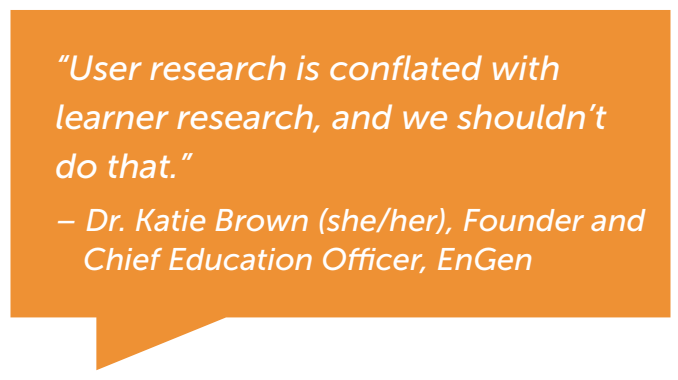
questions when founding the company: What do we know about distance learning? What do we know about language learning? What do we know about using technology for language learning? From there, the EnGen team could build a comprehensive foundation of research. "Taking findings from research intended to answer those three questions and synthesizing them to figure out what we know based on the existing fields of research, we can learn what to extrapolate to make hypotheses," said Dr. Brown.

On top of this, Dr. Brown said, "don't let perfect be the enemy of the good." The best or most fitting research might not be there to answer what you want to know, but all products are a work in progress anyway. "The longer you keep your product around to continue to improve your research design, the better it's going to be," Dr. Brown encouraged. 


\section{Case Study:}

\section{The Long-Awaited Marriage}

Between Research and Practice

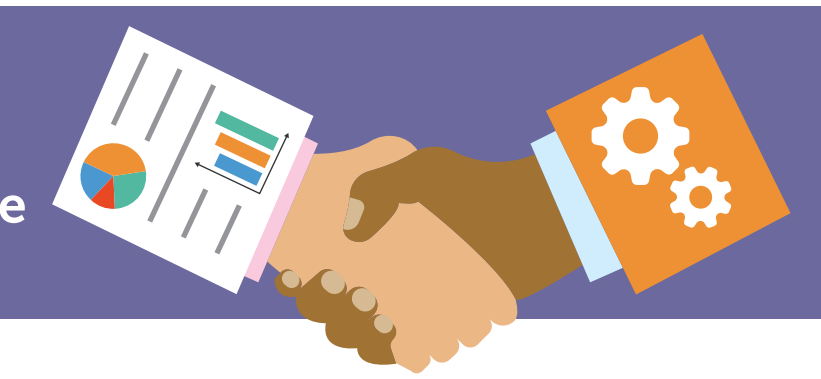

In education, there has traditionally been a gap between research findings - what's deemed "best practice" -and what's actually feasible for practitioners to implement. While scientific studies are invaluable for helping us understand how the mind learns, how students get and stay motivated, and more, these findings are often difficult to implement in the real world. Scientists are, rightfully, careful to construct ideal research settings to reduce interference in their results. At the same time, these ideal settings can be unrealistic for what educators actually face in the classroom. On top of this, valid and useful findings may be published in places that are difficult for teachers to access. For Juliana Hess (she/her), Director of Research and Evaluation at Read to Lead, edtech represents the perfect opportunity to repair the disconnect between learning sciences research and practice. Read to Lead is a workplace scenario game for middle school students that supports their literacy, social-emotional, and occupational identity developments.

Hess described the building process at Read to Lead as a kind of backwards-facing investigation, where the end result is determined first and the steps to get there are found in reverse: "What outcomes do we want for students? How are we measuring those outcomes? What tools do we use to make those measurements?"

"We're looking at quantitative data holistically to understand organizational learning at a higher level."

- Juliana Hess (she/her), Director of Research and Evaluation, Read to Lead Meaningful answers to these questions would be impossible to find without diving into the existing research on learning. Doing so gives confidence to all stakeholders-developers, educators, and investors alike-that the product is both relevant to student needs and at the forefront of educational innovation.

What brings about Read to Lead's marriage with practice is the commitment to iterative improvement. The team constantly gathers data about how their product is being used, stays closely connected with their education partners, and remains engaged with newly emerging educational research. "We're looking at quantitative data holistically to understand organizational learning at a higher level," Hess said. With thousands of-or more-students using an edtech product, developers have a rich source of information about how everyday learners do or do not align with the intended research-driven outcomes, and, by consulting research to learn new approaches, the team can implement adjustments to continuously focus on improving outcomes. Hess also stressed the importance of including active users in the design process. Read to Lead runs an Educators for Research working group and their Innovations Labs. Both setups enable the company to gather further knowledge about how their product is utilized by their partners in real-world settings, strengthening the tie between research and practice. 
To Hess and the Read to Lead team, edtech has the responsibility to engage with and participate in research communities. "We need to understand emerging research," she explained, "and then do our small improvement methods to test what supports that." This philosophy is summed up in Hess' deceptively simple dogma: "design what matters." 


\section{Research-Based Design Product Certification: The Next Iteration}

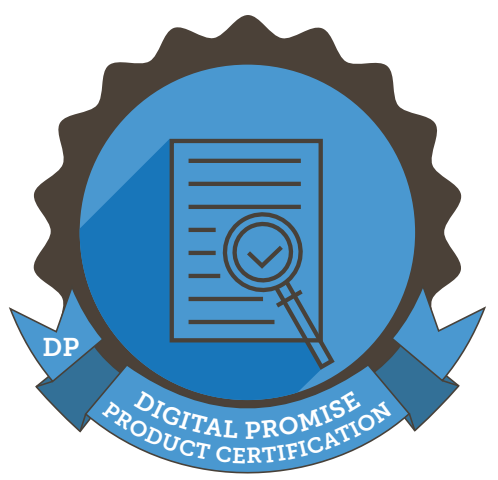

In February 2020, Digital Promise launched its first ever Product Certification to certify edtech products that were grounded in learning sciences research. It has been two years since the certification launch and nearly 60 certifications have been issued since. Our team has learned a tremendous amount about this approach, largely thanks to the insights of educator and education leader partners. We are taking this two year anniversary as an opportunity to incorporate our new insights into the Research-Based Design Product Certification.

Throughout this time, internally, we have also learned more about the ways in which Product Certifications can drive real industry change. By amplifying the priorities of educators, learners, education leaders, and communities, we believe Product Certifications will help edtech companies more clearly understand the needs of their end users, and the certifications themselves will signal the ways in which the product aligns with their needs. We have learned that this ambitious goal relies on the clarity with which we create certification criteria and applications and how we communicate this information to the field.

While the Research-Based Design Product Certification criteria, co-developed with about 50 educators and education leaders across the country, has remained largely unchanged, we have found more straightforward ways to articulate what a product must demonstrate to earn. To do so, we have eliminated jargon and challenged ourselves to find language that resonates with the diversity of individuals impacted by edtech. While the concepts have remained steady, the criteria language now states:

\section{A product that earns this certification will demonstrate the following:}

- Rigorous research about learning informs and drives significant design decisions;

- The product's design philosophy to support learning is grounded in learning sciences research; and

- Education practitioners, learners, and communities can easily access information about the product's research basis.

We have compiled a list of the most commonly asked questions we receive from product applicants to learn how we can better support those interested in applying. A primer was also developed to better define "rigorous research," as well as templates to support applicants in sharing their research basis.

Most important to us in these updates was addressing a concerning question: How might the initial iteration of this certification be perpetuating harm to learners, and particularly, to learners of color? Our team has grappled with the reality that research has historically excluded marginalized communities and presented findings in a deficit-based framing. We saw this as a call to reframe our application to facilitate developers in identifying equity gaps in the research they use and to inspire conversations and reflection about equity in product development. 
Often, edtech companies report the challenge of bridging the gap between existing research and the questions they need to answer in design. We recognize this reality, and acknowledge that creating more constraints for research validity would not be useful. Instead, we created a template where applicants will discuss the learner communities involved in the study and the learner communities who are currently or anticipated to use the product. Our hope is that, by providing an opportunity for products to name the identities of learners involved side by side, teams can see where there are gaps in the research they are using to delve deeper and find new ways to include the voices of learners that are absent from the research. We hope this can spark thoughtful internal conversations for product teams to begin-or continue-working through meeting the full diversity of learners' needs represented across the country.

\section{"When learning science informs our design, we are making}

intentional decisions to develop products and features that account

for the ways we know learners learn best. That intentionality

increases the likelihood that our product will have the impact

we desire, and ensures that our product makes quality learning

experiences accessible to all."

- Matthew Owens (he/him), Head of Curriculum and Content, Composer,

High Resolves 


\section{Conclusion}

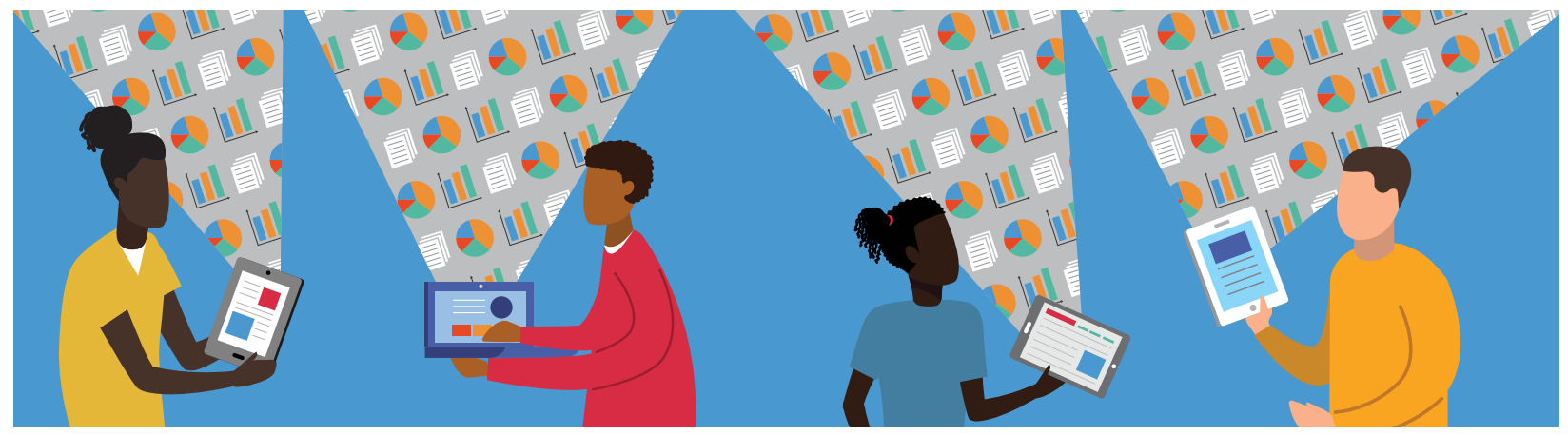

While efficacy research is limited in edtech, both in quantity and generalizability, researchers have found that an intentional connection to learning sciences research drives successful edtech product development. By asking products to describe the intended purpose and research behind their design, consumers can begin to unpack the likelihood that the purpose will match a student's learning need. As seen through the surveys and case studies, products grounded in learning sciences research embrace a spirit of continuous improvement and connection to the educators and learners using their tool, often directly driving design as well. Rather than ask for efficacy studies, our team encourages those researching and selecting edtech to push products to describe the ways in which the tool has been intentionally designed with research as its foundation. Digital Promise's Research-Based Design Product Certification can also be a tool to help assess the quality of edtech products and offers edtech companies an opportunity to clearly share the signal that their tool is grounded in learning sciences research. 


\section{References}

Antle, A. N. (2007). The CTI framework: Informing the design of tangible systems for children. In Proceedings of the 1st international conference on tangible and embedded interaction (TEI '07) (pp. 195-202). Association for Computing Machinery. https://doi.org/10.1145/1226969.1227010

Barone, D., \& Wright, T. E. (2008). Literacy instruction with digital and media technologies. The Reading Teacher, 62(4), 292-302. https://doi:10.1598/RT.62.4.2

Bekker, T., \& Antle, A. N. (2011). Developmentally situated design (DSD): Making theoretical knowledge accessible to designers of children's technology. In Proceedings of the SIGCHI Conference on Human Factors in Computing Systems (CHI '11) (pp. 2531-2540). Association for Computing Machinery. https:// doi.org/10.1145/1978942.1979312

Cheung, A. C. K., \& Slavin, R. E. (2013). The effectiveness of educational technology applications for enhancing mathematics achievement in K-12 classrooms: A meta-analysis. Educational Research Review, 9, 88-113. https://doi.org/10.1016/j.edurev.2013.01.001.

Choi, K. (2021). Sesame Street: Beyond 50. Journal of Children and Media, 15(4), 497-603. https://doi.org/1 $0.1080 / 17482798.2021 .1978675$

Clark, D. B., Nelson, B. C., Chang, H.-Y., Martinez-Garza, M., Slack, K., \& D'Angelo, C. M. (2011). Exploring Newtonian mechanics in a conceptually-integrated digital game: Comparison of learning and affective outcomes for students in Taiwan and the United States. Computers and Education, 57(3), 2178-2195. https://doi.org/10.1016/j.compedu.2011.05.007

Clark, D. B., Tanner-Smith, E. E., \& Killingsworth, S. S. (2014). Digital games, design and learning: A systematic review and meta-analysis. Review of Educational Research, 86(1), 79-122. https://doi. org/10.3102\%2F0034654315582065

Cooney, J. G. (2001). Foreword. In S. M. Fisch \& R. T. Truglio (Eds.), "G" is for growing: Thirty years of research on Children and Sesame Street (pp. xi-xiii). Lawrence Erlbaum Associates.

Dede, C. (2019). Introduction: Improving efficiency and effectiveness through learning engineering. In C. Dede, J. Richards, \& B. Saxberg (Eds.), Learning engineering for online education: Theoretical contexts and design-based examples (pp. 1-14). Routledge.

Erhel, S. \& Jamet, E. (2013). Digital game-based learning: Impact of instructions and feedback on motivation and learning effectiveness. Computers \& Education, 67, 156-167. https://doi.org/10.1016/j. compedu.2013.02.019

Fisch, S. M. (2004). Children's learning from educational television: Sesame Street and beyond. Routledge. https://doi.org/10.4324/9781410610553

Gelderblom, H., \& Kotzé, P. (2009). Ten design lessons from the literature on child development and children's use of technology. In Proceedings of the 8th International Conference on Interaction Design and Children (IDC '09) (pp. 52-60). Association for Computing Machinery. https://doi. org/10.1145/1551788.1551798 
Giannakos, M. N., Horn, M. S., Read, J. C., \& Markopoulos, P. (2020). Movement forward: The continued growth of child-computer interaction research. International Journal of Child-Computer Interaction, 26. https://doi.org/10.1016/j.ijcci.2020.100204

Griffith, S. F., Hagan, M. B., Heymann, P., Heflin, B. H., \& Bagner, D. M. (2020). Apps as learning tools: A systematic review. Pediatrics, 145(1). https://doi.org/10.1542/peds.2019-1579

Habgood, M. P. J., \& Ainsworth, S. E. (2011). Motivating children to learn effectively: Exploring the value of intrinsic integration in educational games. Journal of the Learning Sciences, 20(2), 169-206. https:// doi.org/10.1080/10508406.2010.508029

Hamilton, M., Clarke-Midura, J., Shumway, J. F., \& Lee, V. R. (2020). An emerging technology report on computational toys in early childhood. Technology, Knowledge and Learning, 25, 213-224. https://doi. org/10.1007/s10758-019-09423-8

Hirsh-Pasek, K., Zosh, J. M., Golinkoff, R. M., Gray, J. H., Robb, M. B., \& Kaufman, J. (2015). Putting education in "educational" apps: Lessons from the science of learning. Psychological Science in the Public Interest, 16(1), 3-34. https://doi.org/10.1177/1529100615569721

Hutchison, A., Beschorner, B., \& Schmidt-Crawford, D. (2012). Exploring the use of the iPad for literacy learning. Reading Teacher, 66(1), 15-23. https://doi.org/10.1002/TRTR.01090

Ke, F. (2016). Designing and integrating purposeful learning in game play: A systematic review. Educational Technology Research and Development, 64, 219-244. https://doi.org/10.1007/s11423-015-9418-1

Lee, V. R. (2021). Let's cut to commercial: Where research, evaluation, and design of learning games should go next. Educational Technology Research and Development, 69, 145-148. https://doi.org/10.1007/ s11423-020-09865-3

Manches, A., \& Plowman, L. (2017). Computing education in children's early years: A call for debate. British Journal of Educational Technology, 48(1), 191-201. https://doi.org/10.1111/bjet.12355

Mares, M.-L., \& Pan, Z. (2013). Effects of Sesame Street: A meta-analysis of children's learning in 15 countries. Journal of Applied Developmental Psychology, 34(3), 140-151. https://doi.org/10.1016/j. appdev.2013.01.001

Mares, M.-L., \& Woodard, E. (2005). Positive effects of television on children's social interactions: A meta-analysis. Media Psychology, 7(3), 301-322. https://doi.org/10.1207/S1532785XMEP0703_4

Miller, T. (2018). Developing numeracy skills using interactive technology in a play-based learning environment. International Journal of STEM Education, 5, 39. https://doi.org/10.1186/s40594-018-0135-2

Revelle, G. L. (2003). Educating via entertainment media: The Sesame Workshop approach. Computers in Entertainment, 1(1), 7. https://doi.org/10.1145/950566.950590

Revelle, G. L., Medoff, L., \& Strommen, E. F. (2001). Interactive technologies research at Children's Television Workshop. In S. M. Fisch \& R. T. Truglio (Eds.), "G" is for growing: Thirty years of research on Children and Sesame Street (pp. 215-230). Lawrence Erlbaum Associates. 
Schute, V. J., Ventura, M., \& Ke, F. (2015). The power of play: The effects of Portal 2 and Lumosity on cognitive and noncognitive skills. Computers \& Education, 80, 58-67. https://doi.org/10.1016/j. compedu.2014.08.013

Truglio, R. T., \& Fisch, S. M. (2001). Introduction. In S. M. Fisch \& R. T. Truglio (Eds.), "G" is for growing: Thirty years of research on Children and Sesame Street (pp. xv-xxi). Lawrence Erlbaum Associates.

Zydney, J. M., \& Warner, Z. (2016). Mobile apps for science learning: Review of research. Computers \& Education, 94, 1-17. https://doi.org/10.1016/j.compedu.2015.11.001 